\title{
Volumen 5
}

\section{De l'Humanisme i del Renaixement}

\author{
JULIA BuTiñá \\ (UNED)
}

Este quinto volumen es, según el concepto batlloriano, el último referente a la Edad Media; si bien ello contradice en parte las palabras con que lo prologa Eulalia Duran: «Acabat el cicle medieval amb els quatre volums anteriors, aquest volum $V$ inicia els estudis dedicats a l'Edat Moderna» (V, vii). Este comentario nos queda aclarado en la página siguiente: «com que per a $M$. Batllori l'Humanisme comença el segle XIV, cronoldgicament parlant, part del volum podria haver estat inserit en els volums de l'epoca medieval $»$, a la vez que se nos revela desde aqui que nos hallamos ante un volumen polemico.

Los orígenes del paso que marca el título, que para Batllori se dan en el siglo XV y aún en el XIV, el profesor de la historia de la cultura los consideró siempre fundamentales, como evidencia el hecho de dedicar el primer capítulo, que constituye practicamente la mitad del libro -De l'Edat Mitjana al Renaixement, continultats $i$ innovacions llega a la página 141 - al medioevo cronológicamente hablando. Luego, se extiende al siglo siguiente -En ple Renaixement-, completando el proceso en un breve capítulo de Reflexions sobre la cultura catalana entre el Renaixement i el Barroc. Está claro, pues, que para Batllori aquellos origenes arrancan de la Edad Media.

Difiere, sin embargo, el tratamiento aplicado al vol. IV por Emili Marín y Paula Reig $(2001,34)$, para quienes el tema medieval ocupa sólo los tres primeros volúmenes; el IV, dedicado a La familia Borja, trata de los siglos XIV-XV, pero tiene un primer capítulo El llinatge Borja del segle XIII al XVI (IV, 3-54) que pisa el XVI, hecho que pudiera haber influido en su exclusión.'

Es de suponer que este desbarajuste temporal - tan explícito de que, además de un momento de transición, nos hallamos ante un tema resbaladizo - fue alcanzado por Batllori, quien lo debio aceptar con esa bonhomia transcendental,

1 Aunque parece complicar las cosas es útil, y a la vez congruente con el panorama cronologico que se nos abre, la observacion que hace J. Molas en Miquel Batllori: notes sobre (o per a) una imatge, en Jornades sobre l'obra de Miguel Batllori, Institut d'Estudis Catalans, 1997, 27-28, en referencia a la tendencia de la historiografia moderna por considerar los finales de la Edad Media como las puertas de la Edad Moderna. 
que, más allá aún del humor, le caracterizaba. Si no lo llegó a contemplar incluso complacido por ser próximo a lo que pretendía demostrar: que no hay en ese período una linealidad sino un conjunto de zigzags y matices, como muestra el mismo desconcierto reinante, el cual una aclaratoria nota editorial, inexistente en otros volúmenes, no hace más que confirmar. ${ }^{2}$

Es indiscutiblemente el tema que más le apasiona y, por tanto, es el volumen en que más se implica. Sus propuestas suelen ser aquí rotundas, aunque siempre abiertas a la dialéctica, como provenientes de un buen enemigo de las seguridades, en expresión de $\mathrm{E}$. Duran (V, viii). El autor manifiesta de antemano su actitud de diálogo científico: rels debats $i$ les discussions - no pas les seguretats $i$ les disputes - st que emmenen a un aclariment, per mitjd de la dialectica intel-lectual» $(\mathrm{V}, 3)$. $\mathrm{Y}$, seguidamente, apunta la causa de esta conflictividad: «perque -com han assenyalat sovint diferents historiadors de la cultura - l'època del Renaixement i la seva periodització esquiven a la claredat relativa amb que hom pot parlar de l'Edat Mitjana, del Barroc, de la Il'lustracio o del Romanticisme. I tambe, perque les diferents etapes humanistiques $i$ renaixentistes son més asincrdniques, en els diferents paisos europeus, que no ho són en aquells altres pertodes» (ib.). Refiere asimismo cómo no ocurre así sólo en el tiempo sino también con el tiempo, pues estas discusiones se han ido complejificando en el marco europeo, como expone de Georg von Bellow a Paolo Rossi, en nuestros días.

Por otro lado, es un libro claro y bien estructurado, en que, a pesar del subjetivismo del autor, el lector puede pasearse por temas complejos con paso firme $y$, pese a su profundidad y amplitud, no se pierde. Es tambien donde el autor se mueve con mayor libertad, más a sus anchas, y donde muestra claramente su faceta humanista. Por todo ello, dada la complejidad del tema y nuestro deseo del máximo respeto y fidelidad al autor, a riesgo de caer en alguna repetición, seguiremos la pauta del volumen.

Batllori, buen amigo de gradaciones, aproximaciones y cualquier rasgo que denote las incertidumbres de cualquier hecho humano, es persona idónea para analizar el movimiento inestable por antonomasia, de tránsito. De acuerdo con ello no extrañará que en el primer capítulo de este volumen recoja aspectos varios sin una coherencia total de pensamiento pero con el denominador común de pertenecer a esa cultura intermedia por definicion -insatisfecha con el pasado pero que no se identifica con la modernidad - que se conoce como el movimiento humanista; por ello quizás se ha evaluado como un «pdrtic perfecte» $(\mathrm{V}$, ix), en el que se abren preguntas que no pueden responderse desde una sola disciplina, de modo que cuenta mucho ahf la visión amplia y ponderada del historiador.

En ese capítulo se defienden con firmeza un pensamiento renacentista fuera de Italia, la personalidad del Humanismo hispánico y la precocidad del movimiento en Cataluña. El tono reivindicativo puede derivar del hecho de haberse

2 aqquest llibre inicia una sèrie de nou volums dedicats a aplegar els estudis que Miquel Batllori ha dedicat a l'edat moderna» $(V, 403)$. 
rechazado repetidamente en nuestra península y de que en las letras catalanas ha sido negado por la gran parte de los historiadores de la literatura de los últimos años; según esto, el mundo catalán, en expresión de E. Duran, *hauria passat directament de l'Edat Mitjana al Barroc» (V, ix).

Batllori comprende dentro del análisis humanístico las tres coronas de la península Ibérica; además, esboza una definición de Humanismo, renovadora y amplia, que permite conciliar extremos frente a concepciones restringidas. En el Renaixement $i$ la cultura catalana inserta a ésta en el panorama europeo, principalmente por su proximidad al italiano, y en el proximo subcapítulo trata de $E l$ pensament renaixentista a la Pentinsula Ibèrica. Si a aquél seguía un apunte critico sobre las corrientes actuales de estudio, a éste le hacen de colofón unas 22 páginas de exigente bibliografía, en que fundamenta sus asertos y que alcanza hasta 1964.

Arranca las reflexiones sobre el Renacimiento y la cultura catalana recordando que el primer gran historiador de la filosoffa, Jakob Brucker - para quien se daba una fractura respecto al tiempo renacentista - hacía una excepción con Ramon Llull, rescatándolo del medievo; para ello, se basaba en su influencia sobre médicos y filósofos italianos y alemanes de los siglos XV y XVI. Su teoría del Renacimiento alcanzarfa desde una perspectiva idealista a Hegel, para quien rel Renaixement representa l'Esperit com a absoluta subjectivitat, sobretot amb la seva reivindicacio de la llibertat absoluta» $(V, 5)$. Tras seguir el curso descendiente del fracturismo de Hegel, con sus meandros, aboca a los dos historiadores de la civilización y las artes en que calan aquellas ideas: Jakob Burckhardt y Jules Michelet; el primero influyo en Cataluña a través de Josep Pijoan.

Segín la significacion burckhardtiana, el connubio entre antigledad y modernidad hizo a los hombres más completos, más universales y más inquietamente pluralistas, lo que repercutirfa en un hedonismo, que tuvo claro reflejo en la Corona catalanoaragonesa en un Tirant lo Blanch o en un March. Sigue aquella descendencia, representada sobre todo por De Sanctis, en los distintos páses europeos y, sin dejar de considerar la teorra dicotómica - sostenida entonces desde la historiografia eclesiástica más que desde la cultural-, pasa a fijarse en la que considera más propia para explicar el Humanismo catalán: «la que percebia en el Renaixement una clara diferencia respecte a l'Edat Mitjana, $i$ ddhuc una certa fractura, perd no total» $(\mathrm{V}, 8)$.

En el elenco de nombres que sostienen una continuidad cultural con matices, cita a Pierre de Nolhac, Ernst Cassirer, Eugenio Garin, el historiador Chabod, el filósofo Abbagnano y Oskar Kristeller; próximo a ellos considera a Jose Antonio Maravall, quien setiala unos problemas comunes que son los mismos que en la nueva etapa se resuelven en clave de modernidad; para Batllori, en clave de historicidad. Entre los partidarios de la continuidad, distingue los que están condicionados por supuestos religiosos de los que se mueven en la historia medieval estrictamente; la actitud de ambos la considera fruto de la exageración, contra la exagerada idea rupturista, por tanto también antihistórica.

Es tajante al observar cómo el caso Hvizinga no es apto para aplicarse sin más a todo Europa, pues no se puede juzgar la literatura catalana desde los sermones de san Vicente Ferrer que alli arribaran; su punto de vista, el propio de un 
historiador, se hace obvio al dimensionarlo desde la literatura, ya que obras principalísimas de las riberas mediterráneas - apunto aquí la sucesión de los tres primeros Griseldas (Boccaccio-Petrarca-Metge) o las dos grandes novelas caballerescas, Tirant y Curial - pertenecen más bien a un pujante y florido despegue primaveral que a un otoño que finiquita.

El entronque con el franciscanismo - sostenido por Thode - a causa del descubrimiento de la naturaleza y la influencia de aquél en el advenimiento de la burguesía se ha constatado en rasgos prerrenacentistas y proburgueses en una figura tan medieval como la de Eiximenis. Este enfoque se ha visto avalado recientemente por el profesor Agustín Uña, quien valora la modernidad de las ideas sociopolíticas del dominico valenciano.

Las explicaciones cristiano-burguesas - sigue Batllori- no convencieron a todos los alemanes (Alfred von Martin), aunque a lo largo del siglo XX se ha mantenido el elemento cristiano en el Humanismo (Nicolai Berdjaev, entre otros); en el caso de Toffanin -en una limitación parcial - se ha llegado incluso a identificarlos. Este recorrido nos hace patente lo necesario de estudios como el reciente del último libro de González Rolán (2002) - que tanto he lamentado que no llegara a tiempo de ser conocido por Batllori-, donde, a la luz de la definición y recepción de la tradición clásica, se establecen unas bases conceptuales.

Batllori considera aquí que la negación actual del Humanismo catalán tiene su anclaje en la obra de Curtius, a lo que hace algunas observaciones; como que el Humanismo no consistio esencialmente en la renovación de la enseñanza de la gramática latina, pues esta renovación fue muy lenta, o bien que sólo con el Humanismo comienza en el mundo laico occidental la atracción profunda por la lengua y literatura griegas. Aquí comenta el interés del rey Pedro el Ceremonioso y del infante Juan por el helenismo de la corte aviñonesa, así como, desde el peso de las traducciones en la impregnación del movimiento hacia el mundo laico, observa que antes que Leonardo Bruni ya las había iniciado - tras las huellas de Plutarco y Tucídides - Juan Fernández de Heredia ${ }^{4}$. Y ello, al margen de ser hombre muy medieval, como también lo fuera Canals, excelente traductor del latín.

Desde la política y la historia, reconoce también en los juristas catalanes y valencianos del XV muchas ideas políticas renacentistas, procedentes de Bolonia. Asimismo observa que el nuevo concepto historiográfico alcanza a la cultura

3 «Que lo sepan M. Weber, W. Sombart... y tantos más: el criterio económico del lucro no ha de aguardar el advenimiento del 'espiritu' del protestantismo para hacerse realidad. La modernidad del siglo XIV queda patente en este encomio del mercader con toda su implicación de un profundo giro moral y una nueva etica. Lo formula con inconfundible amplitud y nitidez, mientras bendice la prosperidad de Valencia, un ilustre y amable conversador hispano del siglo XIV: Francisco Eiximenis» (Una, 1995, 68).

4 En el prologo avisaba Duran del hecho de incluir a Heredia - figura que, sin embargo, ya trataron Rubio i Balaguer o Riquer - a la vez que de la originalidad de afiadir a Sibiuda y a Vives; esta última es una de esas figuras sin ubicación al haber vivido en el extranjero y no ser atendida por nuestros historiadores de la literatura. 
catalana desde el renacentista que ejercitaron en Roma el cardenal Margarit y Jeroni Pau, en tiempos de los Borja, y señala en la corte partenopea del Magnánimo obras que pueden hacer de precedente del famoso tratado De dignitate hominis de Pico della Mirandola.

Podríamos abrir aquí un parentesis para comentar que este nuevo concepto de historia es también el que interesa a nuestro autor como historiador, como bien puede probar el que no haya dedicado una atención en profundidad a las crónicas medievales catalanas; el pensamiento batlloriano mantiene siempre la firme unidad de la historiografía junto con la filología y la filosofia, situándose de hecho en la tradición humanística. Lo podemos ratificar asimismo desde los recuerdos que componen sus Memorias de casi un siglo (ed. Quaderns Crema, Barcelona 2001), donde, de los tremendos avatares de los primeros decenios del siglo XX que vivio en su juventud, recoge las inquietudes sociales, pero raramente acusa los hechos de una manera puntual - que es lo que podía esperar el lector, que advierte que ha vivido de cerca tres grandes guerras, las dos mundiales y la de España-; como dice ahi, la historia no le interesó hasta que la estudió como un hecho universal, al margen de la inagotable sucesión bélica, a la que lamentablemente se reducía en viejos tiempos.

En cuanto a la recuperación del diálogo - que tras el estudio de Dionisotti hay que extender a los escritos en lenguas distintas al latín -, insiste en el carácter humanista de Lo somni de Bernat Metge, principalmente por la temática del I libro, la inmortalidad del alma; Di Napoli suscribe esta preocupación como central para toda la filosofía del Renacimiento. Podríamos añadir, subrayando su enfoque, el carácter de la filosofía moral de los tres libros restantes de Lo somni; asimismo, en Metge se advierte ya una separación de la filosofia y la teología, rasgo que Nardi considera que es propio del espiritu moderno, descendiente del averroísmo prehumanístico. Son renacentistas ya, sin embargo, los temas del diálogo posterior de Despuig: Los col-loquis de la insigne ciutat de Tortosa.

La atención a la cultura catalana la cierra Batllori con el recuerdo de Ramón Sibiuda, más bien prerrenacentista que humanista, «per haver centrat el seu pensament en la natura $i$ en l'home, per la seva filosofia natural extrateoldgica, $i$ per haver estat un autor predilecte del més alt pensador renaixentista francès, Michel de Montaigne» $(\mathrm{V}, 20)$, quien le dedicó el ensayo de mayor extensión, el 12 del II libro.

En El pensament renaixentista a la Pentnsula lbérica desmitifica que haya filosofías nacionales antes del siglo XVII; asimismo, descarta que se pueda hablar en rigor de una filosofía renacentista, pues más que de sistema filosófico se trata de una cultura filosofica que es propia al Humanismo y al Renacimiento. En rápida descripción dibuja la expansión del movimiento originado en Italia, que, según las leyes de la geografía y la historia, de la corona de Aragón pasa a la de Castilla y, de aquí, a la de Portugal; así como enumera como focos principales Sicilia, Avinón o Nápoles.

El Humanismo catalanoaragonés, que no fraguó más allá del siglo XV, dejaría dos figuras emblemáticas del Renacimiento hispanico: Juan-Luis Vives y Miguel Servet, uno y otro entre las más altas cotas de madurez y heterodoxia. 
Batllori explica su concepto de Humanismo como una sucesion de textos y doctrinas que reflejan los problemas que el hombre moderno afronta en su lento proceso de separación del mundo medieval; cambio gradual que ofrece un abanico riquísimo en nuestra península a causa de las figuras mixtas - que, como la de Felip de Malla, perfila con perspicacia - y, también, por la convivencia de algunas absolutamente dispares.

Afronta luego problemas que son comunes a las tres coronas en relación con el origen y difusión del Humanismo, la cultura y la ciencia en el Renacimiento iberico, y la espiritualidad renacentista. En el primer momento evalúa como no anecdótica la alabanza del Ceremonioso de la acrópolis de Atenas como el casti1 lo más bello que exista en el mundo y valora la confluencia de la ascendencia helénica con la latina cancilleresca; el ambiente humanístico alcanza a la primera obra castellana - traducida del catalán, como recuerda - de esa encrucijada: Los doce trabajos de Hércules de Enrique de Villena. Sigue la gestación del incipiente Humanismo castellano en la corte napolitana del Magnánimo y en la de su doblemente cuñado, Juan II de Castilla: «és el temps del marquès de Santillana» (V, 31). Y cuando el empuje catalán declina, aparece en Castilla un Nebrija.

Abre continuamente vías de estudio a través de los personajes vinculados a la corona catalanoaragonesa; además de Heredia, el erudito Simón Atumanos - arzobispo de la vieja capital de los dominios catalanes en Grecia - , a quienes admiraba Salutati.

En el aspecto científico da relevancia al papel de Portugal, a causa de las ciencias positivas, que estimularon los descubrimientos. Algunos médicos filosofos esencialmente empíricos descuellan también en el Quinientos de aquella misma «Espanya que al Sis-cents es mantindrd tan tancada al progrés de les ciencies positives» $(\mathrm{V}, 32)$.

Enhebra la descendencia del Humanismo cristiano de Petrarca, palpable en autores de las tres coronas, si bien advierte que es nota común de la cultura ibérica anterior a la muerte de Carlos V (1558) la espiritualidad de sesgo vivista y erasmista; si ambas acusan el origen europeo, la primera es más pía que profunda - aunque más estable por su capacidad renovadora -, frente a la segunda, más intimista e intelectual. Una última mirada a la filología latina - a la sombra de Nebrija todo el siglo XVI - y a las artes plásticas le lleva a formular que en toda la península constatamos rasgos comunes a toda Europa «amb simples matisos nacionals, o si volem, regionals $(\mathrm{V}, 34)$.

En el análisis del pensamiento del Humanismo hispánico comienza por los antecedentes medievales, cuya influencia del judarsmo y mahometismo considera exagerada; sin embargo, reconoce que en la formación de la civilización española se dio una fusión de elementos culturales orientales, lo que ejemplariza con las fábulas moralistas castellanas, el arte luliano en Cataluña o la psicología empírica de Pedro Hispano, el principal filósofo medieval portugués, de sello escolástico. Aquí, a pesar de las escuelas monásticas anteriores, se arranca de la fundación de la Universidad de Lisboa (1290). En Castilla, los primeros estudios generales de Palencia (1184) superaron la precedente escuela catedralicia, si bien dentro de la cultura tardomedieval castellana quien sobresale es Alfonso X el Sabio; bajo su mecenazgo y con 
carácter primordialmente laico, se impulsa la cultura científica alrededor de la Escuela de traductores de Toledo.Como continuación de esta filosofía y cultura palatina, en el siglo XIV, señala los escritos políticos, morales, sociales y psicológicos de don Juan Manuel.

La visión de estos antecedentes en los estados catalanoaragoneses la resume, con las figuras-clave de Llull, Amau de Vilanova y Eiximenis, bajo el epigrafe: Escoldstica, antiscoldstica $i$ política. Batllori atribuye al contacto con Francia e Italia el acentuado carácter escolástico de Cataluña. Caso aparte es Llull, al que define muy exactamente como escolástico independiente, ya que no comparte con éstos el método didáctico ni el argumentativo; frente a él contrasta el pietista franciscano Arnau de Vilanova, en quien sin embargo hay rastros de renovación por su racionalismo y por su interes científico.

Dedica más atención a Metge, hombre ya de pensamiento moderno, que trata bajo el epigrafe de El primer fildsof laic, y cuya principal obra, Lo somni, tan sometida está a la elocuencia - en comentario mío - que ha pasado inadvertida a menudo desde su posición filos6́fica; por otro lado, la plena conciencia de su autonomía ante las fuentes de la christianitas hace de este diálogo una obra humanista, aunque por lo que tiene de triunfo de la humanitas considera que podría quizás verse ya como prerrenacentista.

El siguiente apartado, dedicado al Humanismo catalanoaragonés del siglo XIV al XVI (V, 41-59), es probablemente el más discutido y en el que se nos muestra más contundente. Arranca, como vimos ya, de la percepción helenista antes que latina; según observa, después de Heredia los griegos se difunden de segunda mano. Repasa a continuación las traducciones latinas, en una enumeración que a los filologos nos interesa por presentársenos desde el criterio del historiador, que otorga al hecho de la recepción de aquella tradición una resonancia casi documental, rica en aspectos sociologicos: como Dante y Boccaccio alcanzan mejor las clases medias y es un mercader, Narcís Franc, el traductor del Corbaccio, mientras que el secretario del rey -Metge- traduce el Griselda de Petrarca. El influjo de los trecentistas italianos es tal que, sin ellos, a pesar del bagaje clásico que haya podido impactar en estas tierras, no se explicaría aquí la cultura humanística, conclusión que mis quince ańos de investigaciones sobre esta etapa de introducción del Humanismo no hacen más que suscribir.

Resalta el influjo de las traducciones de estos italianos: la Divina Comedia, en elaborados tercetos, que data de 1428-29 y es la primera completa europea, y la excelente versión del Decamerón, de las mismas fechas. Debo precisar que Batllori cita la literatura alegorica y el Tirant, pero dada la fuerte huella humanista del Curial habría que incluir esta obra indefectiblemente bajo el mismo signo (Butiñá 2001).

Además de citar contactos puntuales italo-catalanes, donde advierte una verdadera convivencia - en la que participan también humanistas castellanoses en la corte del Magnánimo. Ello sirvio ya a Rubio i Lluch para la periodización del humanismo catalán en tres perfodos y por reinados: desde los últimos tiempos de Pedro el Ceremonioso hasta la muerte de Fernando I, el primer Trastámara (1416); el reinado del Magnánimo (hasta 1458, fecha de su muerte); la 
época de Juan II y Fernando el Católico, hasta 1516. Comenta, sin embargo, que podría alargarse a los dos primeros Habsburgo (hasta 1598), pues si bien fue de decadencia para estas letras fue entonces cuando grandes humanistas catalanoaragoneses - Vives, Servet - se afirmaban en Europa.

Al referirse a Lo somni, del que en aquel momento se conocían aún pocas fuentes clásicas - recordemos que este escrito de Batllori cuenta con varios decenios $(V, 27)$ y fuentes muy principales no han aparecido hasta los años $90-$, insiste en su carácter humanista. Me atrevería a afirmar, por tanto, que la firmeza con que lo defendía es la misma con que podemos considerarle a él como humanista; no en vano nos había advertido unas páginas antes que, por muchas fuentes medievales que se descubrieran tras ese dílogo, no puede inscribirse en otro registro. En este punto es tajante: «Encara que es tracti de didlegs ficticis, no sembla possible de dubtar que la inquietud de l'autor per la immortalitat de l'dnima humana responia a una auténtica preocupacio d'un epicuri del primer Renaixement. Perd de tot aixd no es pot deduir l'escepticisme acristid de l'autor $(V, 47)$. Estos comentarios le hacen pionero en efectuar algo tan básico -y que no hab́an hecho los filólogos tampoco hasta el decenio de los 90- como es desdoblar personaje y autor, distinción que, por ejemplo, le lleva a observar que el personaje Metge (en cierto modo, en el libro I, su alter-ego) no discrepa de su interlocutor, el rey Juan, quien defiende la inmortalidad.

Recalco el mérito de su defensa de un Metge humanista, en momentos en que eso suponía ir contracorriente y cuando todavía no se había visto como filosofía platónica del amor la loa de las mujeres -en el IV de Lo somni-, apología que incluye intertextualidades del De senectute y del Convivios; en ese contexto sólo se apreciaba su enérgica antimisoginia, pero Metge iba claramente más allá, bajo una nueva sensibilidad que precede actitudes posteriores. Es más, Batllori añade una observación histórica rotunda, que quizás hemos descuidado los filologos al calificar las ideologías de autores de estas épocas: hasta el V concilio Laterano (1513) la Iglesia no rechaza la actitud aristotélico-averrósta de los que sostenían que la inmortalidad no se podía probar más que por la revelación. Concreción que le permite dar una definición ideológica de Metge como hombre de transición: «al bell mig de l'edat mitjana cristiano-averroista $i$ la critica filosdfica renaixentista $(\mathrm{V}, 48)$.

Al tratar del Humanismo y la espiritualidad asienta que la gran parte de la literatura espiritual de este primer Humanismo está impregnada de espíritu medieval y que, a la vez que se traducf́an a los clásicos, se introducían versiones tan medievales como las de Cavalca y Ubertino da Casale; la Deuotio moderna no llega hasta finales del siglo XV. Veamos una muestra del estilete batlloriano refiriendose a Canals y a Malla: $* E l$ primer fou parcialment humanista $i$ un autor plenament espiritual. El segon fou un escriptor espiritual humanista» (V,

SA este enfoque me he aproximado muy recientemente, segun puede verse en Butifi 2002, 388 390; tambien lo trato en Unes notes sobre Metge, Lull $i$ Juvenal (trabajo que llego a conocer y se ha publicado en el Homenatge a Miquel Batllori 4, «Randa 51, 2003, 7-29) y on Bernat Metge, defensor de la dona il'ideal de la pau, *Revista de Filologia Románica* 20 (2003), 25-40. 
48). Lamenta que se haya perdido el comentario de este último a una obra luliana (Ars memorativa), que hubiera sido muy significativo de sus posiciones, dado que trataba de los aspectos más avanzados de Llull y más apreciados en Europa, el arte de la memoria y la combinatoria. Incluye aqui el Espill de la vida religiosa (1515), que - aunque la firma Comalada - se inclina a considerar anónimo, tal como ha suscrito posteriormente la crítica (Bover 1998, p. 124).

La agrupación de los moralistas laicos se hace necesaria dada la apertura de la ética al mundo del laicismo; incluso textos anticlericales del tiempo del Magnánimo se manifiestan moralistas, con un pie a veces entre las dos moralidades, la medieval y la renacentista. Incluye aqui al poeta Ausiàs March, de sincero trasfondo cristiano, y a dos autores poco conocidos, Francesc Carròs Pardo de la Casta y el barcelonés Benet Garret, Il Cariteo, poeta en italiano, muerto en Nápoles en 1513, y uno de los autores más profundos de la etapa posterior al Magnánimo.

Punto indiscutible de este momento es la renovación y persistencia del lulismo, el cual es nervio que da carácter a estas letras. Para explicarse que Llull sea uno de los pocos filosofos medievales que interes 6 en el Humanismo, aunque alude al aspecto de reformador y crítico de los cristianos, se fija más en el arte combinatorio, que roferia al nou periode de la cultura una possibilitat de trobar la unitat de les ciencies» $(\mathrm{V}, 52)$. Por motivos distintos, los dos principales lulistas del siglo XV, Nicolás de Cusa y Sibiuda, no citan ni una sola vez a Llull en sus obras; si bien no hay que olvidar que durante el siglo anterior había sido condenado por la facultad teológica de París. Para Cataluña, Llull fue sobre todo un filosofo y un teologo; desde 1503, de todos modos, fecha en que se imprime en Barcelona el Directorium inquisitorum de Eimeric, se impone definitivamente su prohibición, que culmina con su inclusión en el fndice, en 1559 , junto con la obra de Sibiuda.

En cuanto al Derecho, señala a finales del siglo XIV la aparición de un renacimiento jurídico, que tiende a una síntesis entre la tradición feudal y el nuevo romanismo. Esta escuela jurídica llevó adherido el cariz político, el cual condujo al concepto de la monarquía pactada; por esta vía se llegará a las doctrinas del cardenal Margarit y su visión humanística de la Hispania clásica.

La decadencia creadora en la corona de Aragón no desdice de lo que reflejara Vives en su despiadada crítica hacia sus congeneres; así, se quejaba de la actitud reaccionaria de los «hispanos» que iban a París a graduarse en la Universidad y volvían «convertits en pseudo-dialectics, és a dir, purs escoldstics» $(V, 56)$. Desde una panorámica internacional salva sólo tres nombres del siglo XVI: Pere Joan Nunyes; el único jesuita salvable, Pere-Joan Perpinyà, y Frederic Furí i Ceriol, el más próximo a Vives a causa de la independencia de pensamiento. Del último destaca que abogaba por la lectura de la Biblia en la lengua nativa, en Valencia, y que, a pesar de las sospechas de herejía, fue siempre bien acogido por los monarcas.

Aunque no fueron filosofos, entendiendo el Humanismo como fenómeno cultural, trata de dos figuras aragonesas: un médico heterodoxo, Miguel Servet, y un historiador, Jerónimo Zurita. En ambos descuella un aspecto que va a imponerse en las ciencias renacentistas: el predominio del sentido crítico por encima del peso de la tradición autoritaria o de la infundada. Servet -el primero 
en exponer la circulación sanguínea - muere quemado como hereje por Calvino. Los Anales de Zurita constituyen la primera obra historiográfica escrita en España con método genuinamente científico y basada en documentos; su prólogo rés un bell epfleg a tota la cultura humantstica i renaixentista de la Corona d'Arag6, sempre projectada cap a Europa» $(\mathrm{V}, 59)$.

Después, se adentra en Vives, a quien tan bien conocía Batllori. Desde los primeros tiempos, como profesor en París, expresa aquél su reacción contra la escolástica y su admiración por la auténtica filosofía; así como también es patente ya su espiritualidad cristocéntrica. En sus años de Lovaina traba amistad con grandes humanistas europeos, como Budé o Erasmo, y por intercesión de Tomás Moro fue preceptor de María Tudor, a quien dirigio rel deliciós tractat, piados $i$ obert alhora, 'De institutione feminae christianae'» (V, 60). Batllori considera su De ueritate fidei christianae como una de las apologías del cristianismo más representativas del Renacimiento cristiano.

A continuación, en De l'Humanisme castelld al Renaixement espanyol, excluye la posición de los que identifican al Renacimiento con el Humanismo laico y que arguyen una ruptura, que de hecho en España no se dio; defiende, pues, un verdadero Renacimiento, que, con sus peculiaridades, comparte con los otros renacimientos europeos un conjunto de caracteres comunes: rel retorn del classicisme, com a forma de cultura, un sentit de ressorgiment politic $i$ una alenada juvenil de l'home» $(\mathrm{V}, 62)$. Entre las causas de que en el conjunto peninsular no hubiera una escisión brusca cita el gusto por lo popular, el afán por la depuración de los textos y la fidelidad a las fuentes, el interés por la pedagogía y las ciencias, y la perfección formal; amén de la perduración de la síntesis cristiana medieval, entendida desde el predominio de lo racional y el alejamiento de la escolástica más vacía. Lo desarrolla en diez puntos:

- Entre l'Edat Mitjana $i$ el Renaixement: situia un precedente del Humanismo en el colegio de San Clemente, obra del cardenal Albomoz (1365), donde se formaron Nebrija, Pinciano o Sepulveda. Medio siglo después, Juan II se carteaba con el Aretino abriendo una puerta al Renacimiento español. Los autores principales son de sobras conocidos: Enrique de Villena y el marqués de Santillana. Menciona también una obra de vínculos medievales, la Visión deleitable de Alfonso de la Torre, por insertarse en la tradición humanística de las visiones filosoficas en un deseo de alcanzar la verdad; esta obra se redacta por indicación del príncipe de Viana, traductor de Aristóteles.

- L'Estat renaixentista del segle XV: aquí observa que en los concilios de Constanza (1414) y de Basilea-Ferrara-Florencia (1431-1445) conectaron los españoles con humanistas italianos y europeos, y considera a Alonso de Cartagena precursor del Renacimiento político espanfol por la afirmación de la preeminencia de España y, en especial, del rey de Castilla sobre el de Inglaterra.

- Cap a la unitat del pensament i la llengua: el ambiente cultural humanístico del reinado de los Reyes Católicos arranca de su interés por el latín. Resalta tres personajes: Cisneros, fundador de la Universidad renacentista de Alcalá, donde imprimió la Biblia políglota; Fernando de 
Córdoba, a quien valoraron Valla y Besarión, y quien aspiraba a la unificación del pensamiento e intentó superar el Arte luliana; y Nebrija, a quien hace descollar en la historia del pensamiento español por el tratado pedagógico, inspirado en Quintiliano, De liberis educando y por el proemio a su Arte de la lengua castellana.

- Les armes $i$ les lletres: selecciona aquí a dos autores representativos del leitmotiv de las armas y las letras: el franciscano fray Antonio de Guevara, pensador renacentista en Reloj de príncipes, donde personifica el tópico humanista de las armas y las letras en el Magnánimo; y Juan Ginés de Sepúlveda, historiador de Carlos V y comentador de Aristóteles, aunque fue más famoso por sus polémicas con Erasmo en contra de Las Casas acerca de las Indias.

- El problema de l'home salvatge d'America: el problema humano derivado de la conquista afectaba a temáticas como la libertad humana y la guera justa. Las Casas, partidario de la libertad de los indios y contrario a la guerra, se oponía a Sepúlveda, que justificaba la lucha de conquista; intervino en la polémica Francisco de Vitoria, añadiendo al sentido cristiano del primero la solidez doctrinal del segundo, lo que le ha valido el título de creador del Derecho internacional. Vitoria, el principal télogo español pretridentino renovó la teología con criterios renacentistas por medio de una exposición elegante y bebiendo en las fuentes directamente.

- L'home i la cultura: humanistes fildsofs: los continuadores de Nebrija en su renovación humanística se inclinaron por uno u otro pensador de la época clásica, pero *tots conserven llur independencia a l'hora de plantejar $i$ de resoldre els problemes més greus de la filosofia, $i$ també els més caracteristics de l'home renaixentista» $(\mathrm{V}, 68)$. Fernando de Herrera en Breve disputa de ocho levadas contra Aristotil y sus secuaces (1517) se presenta como devoto del filosofo pero no como esclavo y se distancia de los glosadores que no filosofan como hombres libres. Y de Pedro Mexfa, amigo de Vives y Erasmo, recuerda sus Diálogos, que analizan los defectos intelectuales y sociales de su tiempo.

Batllori se explica la falta de una escuela platónica similar a la de Ficino debido a la inexistencia de ruptura con la tradición medieval; ahora bien, se aspiro a armonizar aquel pensamiento con el del Estagirita, como se aprecia, incluso en el siglo XVI, en Sebastián Fox Morcillo, de quien - a pesar de fallecer a los 32 años - se comentan aquí varias obras.

- Els metges fildsofs: estos hombres, que caracterizan a la filosofia renacentista española frente a Europa, constituyen una escuela ecléctica e independiente. Proceden del impacto humanista - preferentemente platónico - sobre la filosofía natural basada en la experiencia. Trata de Gómez Pereira, Francisco Valles, Huarte de San Juan y Francisco Sánchez. El último y el primero son precursores de Descartes: Sánchez por practicar la duda metódica como punto de partida y aquél por anticipar el cogito. Las bases cientfficas que empezó a sentar Sánchez - de las que no pasó de la parte negativa y destructiva - ocupan aqur 23 líneas. 
- L'estètica: halla elementos previos de esta ciencia entre los tratadistas y teóricos del arte. En pintura destaca por su originalidad Felipe de Guevara, quien llega a pronunciar juicios estéticos con valor filosófico, como la necesidad de la creación - además de la imitación - para que algo sea artístico y llegue a ser comprendido. Como un caso de humanista que elucubra sobre las artes liberales y cuyas reflexiones se aproximan a la estética cita el tratado de Miguel Sabuco sobre la naturaleza del hombre y las pasiones, que llega a recomendar la música como curativa, pretendiendo liberar a la medicina de antiguas especulaciones y basarla en la naturaleza del hombre.

- Els erasmistes: han podido influir en su ascendencia factores como el ser Erasmo consejero de Carlos V y gozar de una aureola científica, el representar ante la curia romana un ideal reformista que aquí se anhelaba o la elegancia de su programa de reforma, lejos de las revueltas luteranas; o bien que su Humanismo no se detuviera en los clásicos sino que alcanzara al Nuevo Testamento y la Patrística, rasgo que se corresponde con las aspiraciones de la Universidad de Alcalá, su centro de difusión. Tras tratar de su aceptación a través de las capas cultas y populares, se refiere al ambiente antierasmista y cómo la corriente se diluye entre otras líneas espirituales.

Considera que sobresalen por su obra Juan de Vergara, procesado por la Inquisición como iluminado, y Cristóbal de Villalón; pero se detiene especialmente en los hermanos Valdés, Alfonso y Juan, los de mayor alcance europeo. Observa que el testamento del primero lo revela más ligado a la Iglesia de lo que se deduce de sus escritos, de critica eclesiástica y marcados por el sello lucianesco. De Juan comenta que se mantuvo fiel a la ortodoxia católica, a pesar de haberse hallado traducciones clandestinas de Lutero entre sus escritos; de todos modos, es difícil discernir su pensamiento en algunas obras de las que carecemos de original, pues en algunos casos han sido retocadas.

El principal cenáculo erasmiano fue el de Valencia, hasta que la Inquisición, en 1537, frenó su difusión en aquel reino y fomentó los procesos contra algunos, como Conques o Centelles, muy proximos al protestantismo. Anota también que el f́ndice de Pablo IV condenó las obras de Erasmo, pero el del inquisidor español Fernando de Valdés (1559) recogió sólo algunas traducidas a las lenguas vulgares.

- Humanistes espirituals: la època de Cisneros abre en España un periodo de fervor religioso en el que se origina la escuela ascético-mística castellana, que culmina en tiempos de la Contrarreforma (V, 78). Tras la introducción de la Deuotio moderna, surgen los primeros escritores espirituales impregnados de Humanismo cristiano; sobresalen fray Luis de Granada y fray Luis de León, quizás el hombre más representativo del Renacimiento español.

Del Humanismo y Renacimiento portugués comenta que este espíritu, que apunta en el siglo XV, no triunfa hasta el XVI. Las primeras actitudes alejadas de la tradición medieval las sitúa en la prosa didáctica de Dom Duarte. Entre los 
rasgos que aprecia en el libro (Leal conselheiro) que dedica a su mujer, Leonor de Aragón, señala la orientación personal o las relaciones entre la Prudencia y la Justicia. A pesar de esta tímida introducción iba a ser un portugués - aunque afincado en Italia - , León Hebreo, el principal filósofo judío del Renacimiento.

Los grandes descubrimientos, derivados de la escuela náutica de Sagres, hicieron de precedente de otros avances científicos, así como la conciencia de la grandeza del mundo les llevó a dejar las crónicas de corte medieval por la historia humanística y renacentista, con criterio constructivo, crítico y político. Los humanistas se formaban en Europa y reflejaban aquella cultura humanística universitaria - de fuerte sello aristotélico-; entre ellos se halla el primer filosofo portugués de signo humanista: António de Gouveia.

Juan III (1521-1557), que impulsó la reforma de los estudios y creó el Colégio das Artes para el estudio de la filosofía, fue una insigne personalidad del Renacimiento cristiano en Portugal; aquel colegio fue acusado de protestantismo y confiado a los jesuitas en 1555, si bien no fue tal sino un foco de renacimiento erasmista.

Trata en subcapítulo aparte de Juan Fernández de Heredia y el helenismo de la corte de Aviñon; se fija aquí en el matiz humanístico que se desprende de la visión de Heredia acerca de la Hispania clásica previsigótica, que considera incluso como rasgo «que preludia el corrent polftico-cultural del Renaixement* (p. 116), pues en los cronistas medievales la conciencia de que León y Castilla continúan el reino visigodo explica el interés por la historia general de España, mientras que en aquel «la visió historica de tot Espanya, $i$ no solament com a punt de partida per a una histdria dels reis d'Arago $i$ dels regnes que havien conquerit, és un fet completament noux, ib. Este rasgo no se encuentra hasta los Paralipomenon Hispaniae de Margarit, quien además considerará a los Trastámara de Aragón como verdaderos sucesores de la monarquía visigótica ${ }^{6}$. Concluye animando a la tarea pendiente de editar y estudiar mejor todo el scriptorium del gran maestre.

Se centra luego en las relaciones de la corona catalanoaragonesa con los reinos itálicos, fijándose en los elementos comunes a partir de la historiografía, las Universidades, la filosofía, la religiosidad y la espiritualidad. Destaca que los humanistas difundían el pensamiento de la antigledad greco-romana a pesar de la pervivencia escolástica de las Facultades, pero contrasta los reinos italianos a los hispánicos. La cuestión principal y común se centraba en torno a la inmortalidad, acerca de si la inteligencia sola podía probar con certeza que el alma es inmortal, cuestión de todos modos anterior a la filosofía humanista. Si entre los que la defendían estaban Fazio o Ficino, hubo también contrarios a la idea de la inmortalidad; subraya Batllori que para encontrar posturas escépticas o libres,

\footnotetext{
- Recientemente se han desvirtuado algunas versiones de la obra de Margarit (Ll. Lucero Comas, Joan Margarit, Fidel Fita $i$ Robert B. Tate: la dedicatoria del "Paralipomenon Hispaniae, en Miscel-lania d'Homenatge a Modest Prats, I, «Estudi General» 21 (2001), 466-473, pero nose rebate este argumento.
} 
como la de Metge - por ejemplo, las de Pomponazzi, en el Defensorium (1519), posterior, pues, al Laterano-, ha tenido que pasar todo el siglo XV por en medio, pues son ya unos 120 años posteriores a Lo somni.

Observa también que el origen de las diatribas alrededor de la dignidad humana parte de la propuesta del Magnánimo a Fazio y Manetti; aquéllas se prolongarian durante todo el quinientos hasta los últimos manieristas. Se refiere luego a la filosofía del amor, donde contrapone las dos penínsulas, pues aquella filosofía platónica, de moda desde la Florencia de Ficino alcanzó a Nápoles en el siglo XVI, mientras que aquí no llegó a arraigar; si bien ya se ha comentado - por mi parte - la excepción de Metge.

En espiritualidad, sin embargo, otorga la supremacía a los reinos hispánicos sobre los italianos; cita la prosa deliciosa de Isabel de Villena en su Vita Christi - $\tan$ poco conocida y de tanta actualidad por su enfoque eminentemente feminista - junto con poetas mitológicos como Rós de Corella u obras como el tan luliano Espill de la vida religiosa, ya citado, que se difunde por Castilla e Italia con el título de El Deseoso e Il Desideroso, respectivamente.

Sobre los aspectos de transición estudia, a continuación, el diálogo en Cataluña y en Castilla ${ }^{7}$. Comienza distinguiendo los tipos del diálogo luliano (el místico-filosófico y el de controversia), para -después de pasar por los Valdés y otros autores- cerrar con Francisco Cervantes de Salazar, quien trae de nuevo el tema petrarquesco de la dignidad del hombre. Su continuación, en México, según las pautas del diálogo latino a la manera vivista, permite trazar a Batllori - maestro en síntesis - una espiral, con la que enlaza "la literatura dialdgica d'Espanya del segle XVI, de cardcter filosdfic $i$ doctrinal, $i$ la difusio del Renaixement italo-hispanic a la nova Espanya ultraocednica” (V,141).

El segundo capítulo, En ple Renaixement, trata del erasmismo, Llull, Vives e Italia. Aunque, según Eulalia Duran, desaparece aqui el tono reivindicativo (V, $\mathrm{x}$ ), en lo relativo al lulismo de san Ignacio me parece asimismo detectar un tono muy personal.

En Humanisme $i$ erasmisme a Barcelona, 1524-1526 aporta datos muy relevantes para la enseñanza humanística en Barcelona, si bien recuerda que nos hallamos ante la fase provinciana del humanismo catalán, más de un siglo despues de su introducción. Es más, resalta «la insignificanfa de tota la nostra historia - amb una hac inicial petita, petita- en l'època del Renaixement* (V, 172). En esa Barcelona, sin embargo, va a dar relevancia a dos enclaves renacentistas: los cenáculos erasmistas y los lulistas, a los que pudiera chocar considerar como tales. La espiritualidad luliana tomó nuevo impulso en el Renacimiento, al igual que había ocurrido en Francia, en que los lulistas, como Lefevre d'Étaples, eran asimismo erasmistas.

7 Este texto lo tradujo del italiano Jeronimo Miguel y se reprodujo en «A Distancian (UNED, ototio $1995,44-50$ ). 
Apunta aquí el posible primer contacto de san Ignacio con la exigua espiritualidad erasmiana que ahi se respiraba; con ella cerrarfa su primer ciclo de formación, añadiendo ésta a la huella franciscana, procedente del País Vasco y de Castilla, que determinara su cristocentrismo. $O$ sea, funda aqui la aproximación que pudo hacer a la Deuotio moderna, en cuanto a la metodización de la vida espiritual - activa desde principios del siglo XVI en Montserrat- y a la intimidad sosegada de la unión con Dios, por medio de la lmitación de Cristo. La fusión se manifestaria en los Ejercicios como una fuerte tendencia introspectiva que le acerca a los escritores del Renacimiento europeo, sobre todo a Erasmo por el tono *d'afer personal donat al negoci de la salvacio i perfecció espiritual» $(V, 161)$.

Tras tratar del eco de Erasmo, se adentra en Vives, capítulo en el que nos detendremos algo más pues sus comentarios al Vives comentarista del De Ciuitate Dei son muy expresivos de la tónica humanista de Batllori. Se me abre en primer lugar la pregunta, que quedará incontestada, de hasta qué punto - tanto Vives como Batllori- dieron importancia a esta obra por sí misma o por su transcendencia efectiva sobre el Humanismo. Con la solvencia de quien puede anotar amplísimamente los congresos y datos que hacen referencia al tema ${ }^{8}$, nos sitúa en aquella edición y glosa, las cuales Erasmo encomendó a Vives y sufrieron una serie de condenas inquisitoriales a lo largo del XVI. Batllori va a centrar su objetivo en kalguns dels passatges més significatius, referents a quiestions teoldgiques que podien fregar amb les doctrines protestants $i$ amb algunes prdctiques de l'Església catolica que exigien una rapida reforma, ultra a certes expressions eròtiques, ben comunes al Renaixement, perd ja reprovables per la púdica Contrareforma» (V, 192). Ello le llevará a registrar el ambiente antivivista en los comienzos de esta última.

Hay que tener en cuenta que el foco de su atención son unas glosas que no han visto la luz hasta la edición de Valencia («Opera omnia») en conmemoración del nacimiento de Vives, vols. 2 -3 (1992-1994); sin embargo, algunas de ellas - dice - son de tal envergadura que podían haber formado parte de cualquier selección antológica. Según Batllori, la naturalidad del comentario vivista hace que sea uno de los escritos más estimulantes del pensador y donde mejor se aprecia su amplísima cultura y conocimientos, pues a pesar de faltarle a Vives una base de teología sistemática, conocía en profundidad a los autores griegos y romanos que trataba san Agustín.

Desde el primer pasaje Batllori nos transmite la conciencia de Vives de entrar en un campo minado, así como nos expone la conversación que se abre alli a varias bandas: entre los textos, sus comentadores y la controversia reinante a rafz de las reformas. Trata de su confección, de la audiencia y de la peligrosidad con la facilidad de quien conecta con aquella conversación. En el comentario moral sobre la guerra, Vives va con pies de plomo, pues es algo que afecta directamente al pacifismo radical de ambos - de él y de Erasmo-, y a la vez punto neurálgico en una epoca de guerras entre cristianos y contra no cristianos, los turcos. Pero ahi es radical: los impios son los partidarios de la guerra.

- Sobre su conocimiento de la temática humanista se recomiendan los comentarios de A. Hauf sobre Els estudis medievals de Miquel Batllori, en Jornades..., O. cit., Institut d'Estudis Catalans, 1997, p. 41. 
Cualidades de Vives como el ingenio o el seny las capta Batllori en referencia a discusiones desfasadas; asi, acerca de los efectos de la astrología, que todavía coleaba. $O$ bien, relaciona los rasgos psicológicos con los biográficos: así, observa que en el tema del bautismo de los recién nacidos no se deja llevar por la ironía sino que se abre a la duda, pero desprende que tales dudas ren susciten de nostres sobre el moment en què ell mateix havia estat batejat ... ara que sabem amb tota certesa que ell provenia d'una familia hebraica» (V, 197).

Es fina la distinción de Batllori entre los teólogos renacentistas y los medievales en cuanto a la Trinidad, pues para Vives, a pesar del conocimiento revelado del misterio, los cristianos saben muy poco de ese enigma, más profundo que el de la divinidad de Cristo. Reconoce aquí a Vives más filósofo que erudito o historiador del pensamiento a causa del desorden cronológico con que enuncia a los filossofos griegos y romanos en los que habla encontrado indicios trinitarios; y, como seglar que era y en contraste con san Agustín, resalta sus tonos laicos y renacentistas. También recurre Vives a las opiniones de los antiguos al tratar de la Creación, fundándose en los Testamentos acerca del origen del mundo, y más bien adivinándose en lo tocante al fin.

Llama la atención Batllori sobre el hecho de que Vives no mencione a Llull en puntos como estos dos últimos, más aún cuando París era entonces filolulista; ahora bien los diferencia radicalmente - aunque el filosofo mallorquin se guiara por razones metafísicas - en cuanto el valenciano seguía a los clásicos, cosa que revela ya el influjo del Renacimiento. Concluye finalmente Batllori que a los que censuraban a Vives por el hecho de acudir a los autores paganos, se les podía haber dicho que tanto o más recurría Agustín a Varrón, el teólogo de los autores latinos.

Esta dialéctica, de tanto interés para los humanistas, interesaba asimismo mucho a Batllori, por lo que no nos sorprende que considere exagerado que se haya dicho: «que l'Agusti del 'De Ciuitate Dei' era l'Agustt de l'Edat Mitjana, mentre que el de les 'Confessions' serd el del Renaixement» (V, 203). Aunque no podemos descifrar quién lo dijo ni con quién se está discutiendo por no haber bibliografía tras los apartados de este capítulo, me atrevería a apostillar que es una preocupación que le define y que es evidente que parece exagerado, ya que quien mantuviera aquello da por supuesto que la modernidad aboca forzosamente al pesimismo, al igual que hacen las Confesiones; mientras que en la primera obra el rasgo prioritario de modernidad, que se cifra en el recurso a los clásicos, revierte en una interpretación optimista de la Historia.

A su vez, cabría dirimir bajo cuál de las dos obras se alinean preferentemente los humanistas y si distinguimos el Humanismo cristiano y otras cosas que influirían en aquel cariz de considerar como exageración o no aquel comentario. En Metge, humanista de alta exigencia por su racionalismo y clasicismo, por ejemplo, parece estar decantada la alternancia o diferente papel de una y otra obra en función de la perspectiva con que las enfoca, puesto que utiliza una bajo el signo de la introspección - de final oscuro pero indefectible como punto de partida - y la otra desde la conjunción de las distintas tradiciones, donde destacan los paganos-gentiles, como conductores o guías, que le llevará a una postura positiva. 
Quizás desentrañemos algún día por qué se inclinaba Batllori por la importancia del De Ciuitate Dei para la modernidad, por encima de la que marca la reflexión en la interioridad, que parece previa y más general. ¿Porque -como resalta a veces el historiador - los primeros humanistas contestaban con respuestas teologicas a las preguntas filos6ficas y suponía un adelanto una obra que, a pesar de ser una interpretación, busca en la Historia la explicación que no hallaban en el hombre?

La cuestión nos lleva a la relación entre los dos pensadores europeos, pues Batllori entiende bien que Erasmo no hubiese querido glosar aquella obra (como pre-escolástica y pre-medieval) y se la hubiese encomendado a Vives; así como se congratula del acierto, dado que el de Rotterdam quizás no habria salido incólume de puntos difíciles para san Agustín, como la condenación, la predestinación o el pecado original, pero que no subyugaron a un espíritu claro y mediterráneo: «Amb la claredat de la seva ment, Vives podia passar $i$ passejar impertorbable entre els capttols obsessius de sant Agusti, com entre els calitjosos canals de Bruges, on encara reposen les seves cendres $(\mathrm{V}, 203)$. Y ello nos recuerda de nuevo el papel de precedente de Bernat Metge, de quien podemos decir algo parecido, por haber podido flotar por encima de medievalismos intentando distinguir un hilo de luz que reconocemos de la tonalidad que caracterizaba a los humanistas posteriores. Esta asepsia - dice - es privilegio de algunos hombres que, en el quicio de una nueva etapa, pueden llegar a intuirla. $Y$ así Vives nos traslado, con las elucubraciones teológicas de san Agustín, un tesoro de erudición clásica junto con su fina y humana calidad interpretativa.

Algunos contrarreformistas reprocharon la actitud de Vives, por ejemplo, por incluir textos que considerarian picantes o excesivamente carnales, pero ello le sirve a Batllori para demostrar «que si, en general, els jueus espanyols havien sabut hispanitzar-se amb la convivencia $i$ amb els quefers diaris, els jueus valencians havien aconseguit fins $i$ tot valencianitzar-se» $(V, 204)$.

El crecimiento de la bibliografía vivista - tras haber publicado la de la Grande Antologia Filosofica de 1964- provocó un nuevo simposio en Wolfenbuttttel, en 1980, el cual reseña aquí, dejando sentado de antemano que el presidente del coloquio, August Buck, al abrirlo, afirmo que Vives era el mayor humanista español. Añade, de todos modos, que Vives no se puede ver como el principal humanista valenciano, catalanoaragonés o español, porque pertenece al Renacimiento europeo.

Al referirse a Joan-Lluts Vives en l'Europa d'avui hace otras precisiones importantes de índole general: cómo, a pesar del estudio de Curtius, que constata la pervivencia de los elementos clásicos en el medioevo, y del poso medieval de las figuras mixtas, se observa en éstas que sus actitudes y preferencias ya no son las de la Edad Media. También rechaza aquí la teorfa que hace provenir el Humanismo español de Nebrija, pues ello se debe al error de no tener presente que tanto el Humanismo italiano como el nuestro eran extrauniversitarios -e incluso antiuniversitarios - ; es decir, se debe a confundir el inicio del Humanismo con el de su mayor difusión, a través de las Universidades. 
Todavía en pleno Renacimiento, trata de la cultura de Cerdeña, Sicilia y Nápoles en relación con los otros estados catalanoaragoneses, a los que estaban tan vinculados en esta época. Y cierra tratando de la historia y la literatura en Italia: sobre Ferran el Catdlic $i$ el Reialme de Napols y sobre El IV centenari ariostesc a Ferrara (1533-1933). La descripción de la villa en que murio Ariosto, en esta ciudad, y en la que se habla efectuado la exposición de sus obras y ediciones permite revivir ésta con toda atención y deleite, pues pormenoriza, con afecto y admiración, códices, frescos, medallas, grabados y objetos; paseamos, pues, nuestra mirada con la misma curiosidad y afecto culturalistas que él cuando - un joven de veintipocos años - la visitara.

Finalmente nos ofrece un digno colofón para un libro sobre el Renacimiento: los bellos retratos de Quatre estudiosos del Renaixement: Marcel Bataillon, Eugenio Garin, Delio Cantimori y Jordi Rubi6. Retratos del natural, pues a todos ellos los conoci6 personalmente.

Alude después, entre las Notes crítiques, a los problemas de la investigación en torno al Humanismo y Renacimiento, hipermitificados por todos lados y, tras negar el apriorismo de una historia del pensamiento, aboga por una nueva historia de la cultura, gracias a la ampliación de los horizontes y la profundidad de las reflexiones humanas.

Quiero cerrar comentando que el recorrido descrito no ha sido aprovechado aún en su plenitud, al menos desde los estudios filológicos; y no me refiero tanto a su aceptación como a la presencia y a la discusión. Es decir, se cumple en él mismo lo que tanto advertía él como negativo: la filología hoy es restringida y suele prescindir del hecho cultural. Sin embargo, si se asume ya hoy por lo general que la ruptura de los tiempos no fue tal, al menos fuera de Italia - si es que alli llego a serlo-, se deduce que no es válido simplificar la partición, y hay que recurrir a matices, desde una generosa amplitud de enfoques, y a escalonamientos graduales, en un panorama altamente diversificado. Cosa que empezo a hacer Batllori, gracias a las finas relaciones propias del buen historiador, que podrian ofrecer vías nuevas a otras especialidades.

Batllori, que se aproximo tanto al Humanismo y al Renacimiento, nos ha dejado un buen regalo a sus estudiosos. No toca por nuestra parte más que agradecer al profesor de historia de la cultura el habernos ofrecido tan sólido y bello apoyo, que es lo que puede aspirar a ofrecer un historiador que ha perseguido estudiar los hechos de los hombres. Y, tras valorar la síntesis batlloriana, simplemente desde lo que me ha costado a mi la tarea muchísimo más simple de sintetizar sus páginas -éstas que publicamos son menos de la cuarta parte de la primera síntesis realizada -, cierro con las palabras de la prologadora, que a mi entender ha sabido valorar lo que de innovador tiene el volumen: "Un llibre aixt, que abasta tots els camps del pensament, que te en compte escrits en llenglies diverses, en especial el llatt humantstic, que sap vincular estretament el present $i$ el passat, ha estat possible grdcies a diversos factors que concorren en el pare Batllori: un coneixement personal dels grans historiadors europeus recents - fet que li ha permes de situar els temes en la polèmica interpretativa no d'una manera distanciada i aseptica sinó prenent una posició determinada, respectant, aixd st, les diverses interpretacions- $i$ un 
domini en els diversos camps del pensament, facilitat per la seva trajectòria vital que l'ha situat predominantment a Roma $i$ l'ha vinculat als grans centres historiogrdfics, $i$ li ha proporcionat un coneixement viu dels estudiosos, dels arxius $i$ biblioteques $i$ estar al corrent de les darreres orientacions historiogrdfiques. El lector té, doncs, a les mans un llibre no solament instructiu, sino un llibre per a reflexionar sobre els grans problemes culturals de la historia, en aquest cas, sobre el pertode que es considera com l'inici del mon modern. Un llibre, per tant, per a llegir i rellegir» $(\mathrm{V}, \mathrm{xi})$.

\section{REFERENCIAS BIBLIOGRÁFICAS}

AlCOBERRo, A., Miquel Batllori, Fundaci6 Catalana per a la Recerca, Barcelona 2000.

BATLLOR, Humanismo y Renacimiento, ed. Ariel, Barcelona 1987.

BatLlori, M., y GARCta VILLOSLADA, R., Il pensiero della Rinascenza in Spagna e Portogallo, en Grande Antologia Filosofica, VI, ed. Marzorati, Milan 1964, 297-657.

BOVER, A., La época del Renacimiento y el manierismo, en Literatura Catalana, II, coord. por J. Butixá, UNED, Madrid 1998.

BUTINÁ, J., En los origenes del Humanismo: Bernat Metge, UNED, Madrid 2002.

ID., Tras los ortgenes del Humanismo: El «Curial e Gulelfa», UNED, Madrid 2001 3 (1991).

CHABOD, F., Escritos sobre el Renacimiento, Fondo de Cultura Económica, México 1990 (19671).

GONZÁleZ ROLAN, T.; SAQUERO, P., y LOPEZ FonSECA, A., La tradición clásica en Espaha (siglos XIII-XV). Bases conceptuales y bibliograficas, ed. Clásicas, Madrid 2002.

InstTTUT D'Estudis Catalans. Secci6 Historico-arqueoldgica, Jornades sobre l'obra de Miquel Batllori, Barcelona 1997.

MARIN, E.; REIG, P., Miquel Batllori: la memòria recent, en VV AA, La saviesa de Batllori, ed. Sá, Valencia 2001, 11-36.

Riquer, M. de, Histdria de la Literatura Catalana, II, ed. Ariel, Barcelona 1964.

RUBIÓ I LLUCH, A., Joan I humanista i el primer periode de l'humanisme catald, «Estudis Universitaris Catalans» X (1917-18), 1-117.

UNA, A., Eiximenis: moral y moralidad en la gestión pública, «Cuadernos Salmantinos de Filosofia» XXII (1995), 51-68. 